ISSN 0103-8478

\title{
Eficiência energética de um trator agrícola utilizando duas configurações de tomada de potência
}

\author{
Energy efficiency of a tractor using two configurations of power take-off
}

\author{
Ulisses Giacomini Frantz ${ }^{I^{*}}$ José Fernando Schlosser ${ }^{\mathrm{II}}$ Marcelo Silveira de Farias ${ }^{\mathrm{I}}$ \\ Letícia Frizzo Ferigolo ${ }^{\mathrm{III}}$ Leandro Correia Ebert ${ }^{\mathrm{III}}$
}

\section{- NOTA -}

\section{RESUMO}

A tomada de potência (TDP) de um trator agrícola tem por principal finalidade transmitir a potência gerada no motor, para acionamento de órgãos ativos das máquinas agrícolas. Tendo em vista a necessidade de se aumentar a eficiência energética na agricultura, alguns fabricantes disponibilizam para os agricultores uma configuração de TDP que proporciona o acionamento dessas máquinas a um regime de rotação menor do motor do trator. Assim, a rotação da TDP é mantida podendo-se obter uma redução do consumo de combustível. Este trabalho objetivou quantificar o consumo de combustível de um trator agrícola, operando com duas configurações de TDP (normal e econômica) em duas áreas agrícolas de relevo distinto. Como resultado, evidencia-se que, com a utilização da TDP econômica, tanto o consumo horário quanto o consumo operacional de combustível, em ambas as áreas trabalhadas, foi menor quando comparado à TDP normal.

Palavras-chave: consumo de combustível, TDP econômica, máquinas acionadas pela TDP.

\section{ABSTRACT}

The agricultural tractor power take-off main purpose is to transmit the power generated in the engine to drive the active organs of farm machinery. In view of the need to increase the energy efficiency in agriculture, some manufacturers provide for farmers a power take-off with economy mode, which provides to the drive these machines at a reduced engine rpm. Thus, the PTO speed is maintained and can obtain a reduction in fuel consumption. This research aimed to quantify the fuel consumption of a tractor with two power take-off configurations in two agricultural areas with different reliefs. As result, it is evident that the use of economy mode, both hourly fuel consumption and operational fuel consumption in both areas worked less when compared to standard power take-off.

Key words: fuel consumption, economy PTO mode, machines driven by $P T O$.
A crescente preocupação da sociedade mundial com o ambiente origina uma pressão sobre o uso de combustíveis fósseis, que são os grandes responsáveis pela emissão de gases poluentes na atmosfera. Vários países estão buscando reduzir ao máximo o uso desses combustíveis, seja pela substituição do produto ou pela adição de outros combustíveis para diminuir a carga poluidora (MAULE et al., 2001).

Em função dos custos dos combustíveis, potencial poluidor gerado pela queima destes, e necessidade de diminuir o consumo de energia, faz-se necessário que sejam desenvolvidas formas alternativas de gerenciamento das atividades agrícolas, mais especificamente da principal fonte de potência para estas, o trator. A utilização do trator, dentro da propriedade agrícola, é muito diversificada e a busca otimizada de seu desempenho se justifica (VALE et al., 2011).

$\mathrm{Na}$ escolha do trator ideal para realizar as operações agrícolas, podemos avaliar diversos itens, como potência, conforto, manobrabilidade, facilidade de manutenção e preço de aquisição, sendo que o conhecimento da eficiência energética do trator poderia ser mais um item a ser considerado em sua seleção (SILVEIRA \& SIERRA, 2010). Uma forma prática de verificar essa eficiência consiste em expressar, a campo, a quantidade de combustível consumida pelo trator durante uma determinada operação agrícola.

\footnotetext{
IPrograma de Pós-graduação em Engenharia Agrícola (PPGEA), Universidade Federal de Santa Maria (UFSM), 97105-900, Santa Maria, RS, Brasil. E-mail: ulissesgf@hotmail.com *Autor para correspondência.

IIDepartamento de Engenharia Rural (DER), Centro de Ciências Rurais (CCR), UFSM, Santa Maria, RS, Brasil.

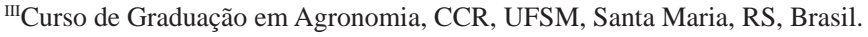
Recebido 07.02.13 Aprovado 02.12.13 Devolvido pelo autor 17.04.14 CR-2013-0175.R1
} 
De acordo com SIEMENS \& BOWERS (1999), os custos com combustível e lubrificante representam, no mínimo, 16\%, chegando a atingir 45\% dos custos totais das máquinas agrícolas, dependendo do tipo de combustível e do número de horas trabalhadas. Diferentes consumos de combustível podem ser obtidos para o mesmo tipo de trabalho, dependendo da marcha utilizada (HANSON et al., 2003).

Com base nos ensaios dinamométricos, através da tomada de potência (TDP), pode-se obter o valor do consumo específico de combustível em pontos determinados do funcionamento do motor (SILVEIRA et al., 2008). Ainda segundo o autor, estes pontos se referem ao percentual da potência e rotação do motor em relação à potência nominal. Porém, ensaios a campo são a melhor forma de avaliação e podem expressar de maneira mais precisa o consumo de combustível.

O trator agrícola é uma máquina de tração que fornece potência aos implementos agrícolas. O sistema de transmissão é o conjunto de elementos que garante a transmissão de potência do motor para os diferentes sistemas a se utilizar, como: o sistema hidráulico, a TDP e as rodas motrizes (MÁRQUEZ, 2004).

Recentemente, muitos fabricantes passaram a disponibilizar aos produtores rurais, tratores equipados com a chamada "TDP econômica”, que, diferentemente da TDP considerada normal ou convencional, aciona uma máquina agrícola, mantendo a mesma rotação padronizada da TDP a uma rotação mais baixa do motor. Porém, devido à baixa rotação do motor, a utilização desta configuração de TDP se limita à execução de operações agrícolas leves, utilizando equipamentos como pulverizadores, roçadoras, distribuidores centrífugos, entre outros.

Devido à necessidade de buscar-se uma maior eficiência energética nas operações agrícolas, este trabalho teve como objetivo avaliar o consumo de combustível de um trator agrícola utilizando TDP econômica e TDP normal, em duas áreas de relevo distinto na aplicação de fertilizantes a lanço. Os dados foram coletados na safra agrícola 2011/2012 com a cultura do trigo (Triticum aestivum L.).

Para a realização do experimento de campo, foi utilizado um trator agrícola da marca Massey Ferguson, modelo MF 4283 com tração dianteira auxiliar (TDA), com potência máxima de 62,50kW do motor, pneus dianteiros 12.4-24 R1 e traseiro 18.4-34 R1. O distribuidor centrífugo utilizado foi da marca Massey Ferguson, modelo MF 2013 M com acionamento hidráulico, com capacidade de 1.300 litros e largura de trabalho de aproximadamente 20 metros, para o tipo de produto aplicado, que era fertilizante nitrogenado (ureia) na dose de $200 \mathrm{~kg} \mathrm{ha}^{-1}$.
Para quantificar o consumo horário de combustível, utilizou-se um fluxômetro, marca Oval, Flowmate (OVAL M-III), modelo LSF 41L e o sistema utilizado para aquisição desses dados foi um datalogger da marca Campbell Scientific, modelo CR1000, para armazenar os dados do gerador de pulsos (fluxômetro), conforme esquema da figura 1A, em que as informações foram registradas continuamente em um período de aquisição de 2 segundos.

O consumo operacional de combustível foi determinado por meio da relação entre o consumo horário de combustível e a capacidade de campo efetiva, conforme (MIALHE, 1974). A capacidade de campo efetiva foi determinada pela relação entre a área útil da parcela trabalhada e o tempo gasto no percurso da parcela.

O experimento de campo foi conduzido em duas áreas (uma área de relevo considerada plana, com inclinação de $2^{\circ}$, e outra de relevo com declividade suave, com 13,6 $6^{\circ}$ utilizando duas configurações da TDP do trator (econômica e normal). Para equalizar as velocidades de deslocamento e o regime de rotação da TDP (econômica e normal) em 540 RPM, predeterminou-se o regime de rotação em 1900RPM no motor e a $3^{\text {a }}$ marcha do grupo de reduzida baixa para a TDP normal e 1700RPM no motor e a $3^{\text {a }}$ marcha do grupo reduzida alta para a TDP econômica. Esse procedimento foi realizado através de um tacômetro foto/contato digital da marca Minipa, modelo MDT2238A. Cada unidade experimental totalizou 4 minutos de percurso, o que consistia num circuito vai e vem (aclive e declive), conforme o tratamento a ser realizado (Figura 1B).

Para a análise estatística, foi considerado um experimento bifatorial, em que os fatores foram: configuração da TDP (normal e econômica) e Área (plana e declividade suave), em delineamento experimenal blocos o acaso, com três repetições. Após, os dados (consumo horário e consumo específico de combustível) foram submetidos à análise de variância e ao teste Tukey de comparação de médias em nível de 5\% de significância e realizadas com o auxílio do software Sisvar, versão 5.3 (FERREIRA, 2008).

Para a variável consumo horário de combustível, não houve interação entre os fatores Área e configuração da TDP. Dessa forma, os dados são analisados separadamente. Durante a utilização da TDP econômica $\left(7,00 \mathrm{~L} \mathrm{~h}^{-1}\right)$, houve diferença estatística no consumo horário de combustível, ocorrendo uma redução de 11,25\% em relação à utilização da TDP normal $\left(7,89 \mathrm{~L} \mathrm{~h}^{-1}\right)$. Em relação ao fator Área, houve diferença estatística para este fator, em que o experimento foi instalado na área 


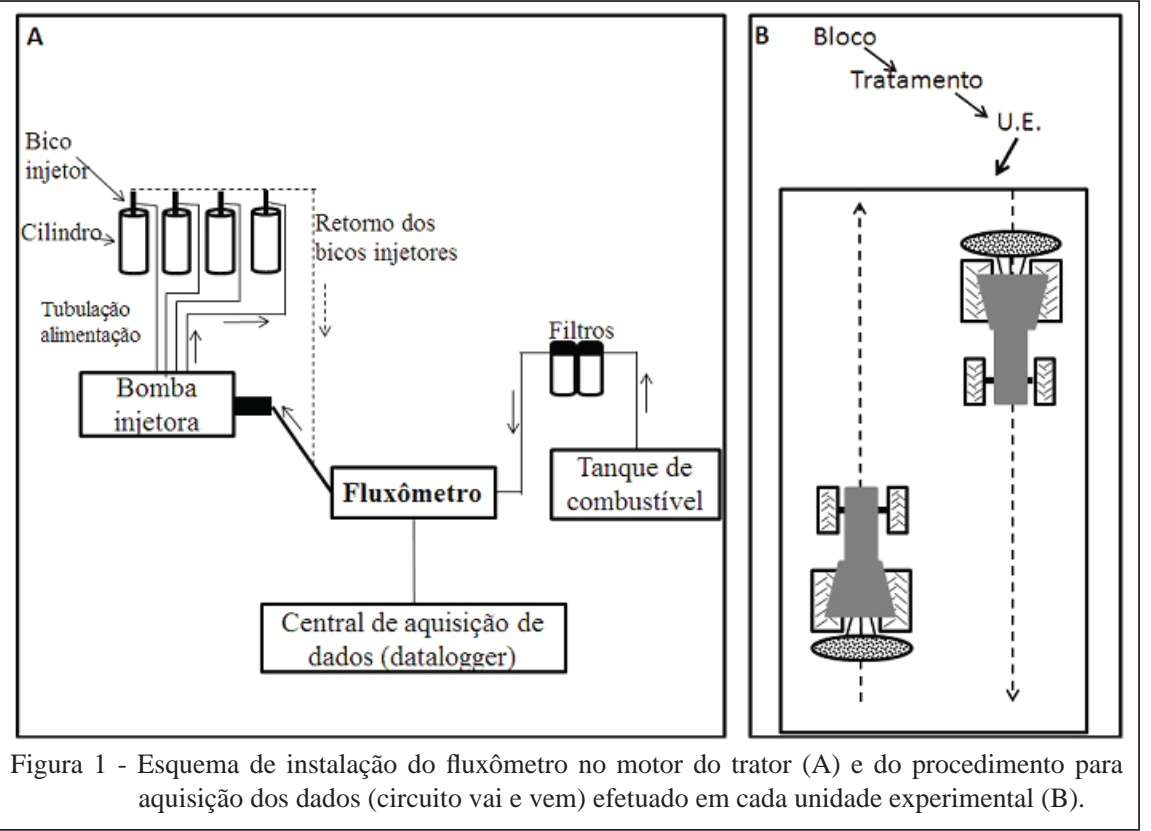

considerada plana $\left(6,81 \mathrm{~L} \mathrm{~h}^{-1}\right)$, quando se obteve um valor de consumo horário 15,6\% menor do que na com declividade suave $\left(8,07 \mathrm{~L} \mathrm{~h}^{-1}\right)$. Isso pode ser explicado pelo menor esforço do motor do trator, devido à inexistência de aclives acentuados da primeira.

Com relação ao consumo operacional, percebe-se que não houve interação entre os dois fatores avaliados. Assim como ocorreu para os dados de consumo horário, quando se estava utilizando a configuração de TDP no modo econômico, esta proporcionou uma economia de $11,43 \%$ no consumo operacional, em comparação com a utilização da TDP normal (Tabela 1). Os valores de consumo operacional são relativamente baixos em função da largura de trabalho da máquina agrícola ser elevada (20m). Analisando-se os dados referentes

Tabela 1 - Consumo operacional (L ha ${ }^{-1}$ ) para os fatores configuração da tomada de potência do trator e Área.

\begin{tabular}{lc}
\hline & \multicolumn{2}{c}{ Consumo operacional $\left(\mathrm{L} \mathrm{ha}^{-1}\right)$} \\
\hline------------------- \\
TDP Econômica & $0,5823 a$ \\
TDP Normal & $0,6575 b$ \\
----------------- \\
Área plana & $0,5675 a$ \\
Área declividade suave & $0,6723 b$ \\
CV $(\%)$ & 3,17 \\
\hline
\end{tabular}

Médias não seguidas da mesma letra minúscula na vertical diferem a 5\% de significância, pelo teste de Tukey. as duas áreas trabalhas, nota-se a mesma tendência, isto é, quando operando na área considerada plana o consumo operacional foi reduzido em 15,59\%, quando comparado à área com declividade suave. Esses valores, tanto para o consumo operacional quanto para o consumo horário, são uma média das duas configurações de TDP (normal e econômica).

Conclui-se que a utilização de TDP econômica pode reduzir o consumo horário e operacional de combustível, bem como, é influenciada pelo relevo da área.

\section{AGRADECIMENTOS}

Os autores agradecem ao apoio financeiro recebido da Coordenação de Aperfeiçoamento de Pessoal de Nível Superior (CAPES) e Conselho Nacional de Desenvolvimento Científico e Tecnológico (CNPq). Também à Your Agriculture Company (AGCO do Brasil) pela disponibilização do trator e implemento agrícola utilizados neste trabalho.

\section{REFERÊNCIAS}

FERREIRA, D.F. Sisvar: um programa para análises e ensino de estatística. Revista Symposium, v.6, p.36-41, 2008. Disponível em: <http://www.fadminas.org.br/symposium>. Acesso em: 04 jan. 2013.

HANSON P.A.M et al. A methodology for measuring the effects of transient loads on the fuel efficiency of agricultural tractors. Applied Engineering in Agriculture, v.19, n.3, p.251-257, 2003. Disponível em: <http://dx.doi.org/10.13031/2013.13657>. Acesso em: 23 nov. 2013. doi: 10.13031/2013.13657.

MÁRQUEZ, L. Las transmissiones: el escalonamiento de las marchas. Agrotécnica, n.10, p.55-62, 2004. Disponível em: 
$<$ http://dialnet.unirioja.es/servlet/articulo?codigo=2919153>. Acesso em: 23 nov. 2013.

MAULE, R.F. et al. Produtividade agrícola de cultivares de canade-açúcar em diferentes solos e épocas de colheita. Scientia Agricola, v.58, n.2, p.295-301, 2001. Disponível em: <http:// www.scielo.br/pdf/sa/v58n2/4420.pdf>. Acesso em: 23 nov. 2013. doi: 10.1590/S0103-90162001000200012.

MIALHE, L.G. Manual de mecanização agrícola. São Paulo: Agronômica CERES, 1974. 301p.

SIEMENS, J.C.; BOWERS, W.W. Machinery management: how to select machinery to fit the real needs of farm managers. East Moline: John Deere Publishing, 1999. 5p.
SILVEIRA, G.M.; SIERRA, J.G. Eficiência energética de tratores agrícolas fabricados no Brasil. Revista Brasileira de Engenharia Agrícola e Ambiental, v.14, n.4, p.418-424, 2010. Disponível em: <http://www.scielo.br/pdf/rbeaa/v14n4/v14n04a11.pdf>. Acesso em: 03 fev. 2013. doi: 10.1590/S1415-43662010000400011

SILVEIRA, G.M. et al. Classificação dos tratores agrícolas de pneus em função de sua eficiência energética. Engenharia na Agricultura, v.16, n.2, p.208-214, 2008. Disponível em: <http:// www.seer.ufv.br/seer/index.php/reveng/article/viewFile/18/8 > . Acesso em: 23 nov. 2013. doi: 10.13083/1414-3984.v16n02a0.

VALE, W.G. et al. Desempenho operacional e energético de um trator agrícola durante a operação de roçagem. Global Science and Technology, v.4, n.2, p.68-75, 2011. Disponível em: $<$ http://rioverde.ifgoiano.edu.br/periodicos/index.php/gst/article/ view/422>. Acesso em: 23 nov. 2013. 